\title{
Философский аспект влияния информационных технологий на общественное развитие
}

\author{
Самира Дадашова \\ Институт Философии НАНА, Баку, Азербайджан \\ samira_889_87@mail.ru
}

\begin{abstract}
Аннотация- В данной статье рассмотрены наиболее важные социальные проблемы современного общества, вызванные информационными воздействиями на индивидуальное и общественное сознание. Цель заключается в том, чтобы обратить внимание научного сообщества на философский аспект данной проблемы и ее нравственноэтическую составляющую.
\end{abstract}

Ключевые слов - информационные технологии, личность, манипуляция сознанием, этика

\section{I. ВВЕДЕНИЕ}

Подвергая философскому осмыслению современную стадию научно-технической революции, ученые обозначали нынешний век как эпоху информации и исследований возможностей мозга. Новыми орудиями, которыми человек совершенствует внутреннюю и внешнюю природу оказались нано-, инфо- и биотехнологии, и основа всего - квантовая теория. Уже сегодня квантовая теория привела современное общество к лазерной и цифровой революции. Однако наука как двухсторонний нож, порождает не меньше проблем, чем решает: новые возможности граничат с возрастающими опасностями для самого человека. Потому проблематичность человеческого бытия с каждым годом, с каждым новым открытием в науке приобретает новые параметры. Развитие технологий, в том числе и информационных, создало условия для улучшения качества жизни, но в то же время, явилось предпосылкой для более изощренной эксплуатации физических и умственных способностей человека, для манипуляции сознанием. В результате формируется идеология постмодернистской морали с тотально прагматическим отношением к человеку, блокирующее его право на индивидуальное своеобразие и свободу. Притом, чем большей информацией о человеке мы владеем, тем меньше у него свободы, а стало быть, тем в большей опасности он находится. Не удивительно, что на этапе стремительного развития информационного социума существенный характер приобретают проблемы обеспечения информационной неприкосновенности границ частной жизни как некого неотъемлемого элемента свободы индивида.

\section{II. ОСНОВНАЯ ЧАСТЬ}

Российский философ В. Кутырев в переходе к компьютерно-информационному обществу, или Техносу, как он его называет, видит подлинный кризис гуманизма, ибо происходит замена предметной среды обитания человека - виртуальной, вещей - симулякрами, духовности - расчётом, культуры - технологиями[1]. Неслучайно сегодня большой резонанс вызывают вопросы регулирования этико-правовых аспектов новейших технологий. Становление компьютерного века и информационного общества находят растущую конвергенцию в трансформации и коммодификации человека. Однако будут ли новейшие технологии иметь нежелательные последствия зависит от нашего морального принципа непричинения вреда человеку и обществу. Сложность оценки технологий заключается в том, что большинство из них не были созданы с дурными целями. Но, как и всякая новая технология, будучи «улучшением», неизбежно несет в себе смысл выхода за пределы того, что существует в определенный момент, будь то определенное положение вещей, или функция тела, или общее ограничение, встроенное в человеческую природу. Так произошло и с технологией чипирования, успешно применяемой в некоторых странах Запада, и, в особенности, в США и Швеции. Технология чипирования, созданная для терапевтических и диагностических целей, преодоления конкретных физических или психических недостатков индивидов (например, проверка уровня сахара в крови, давления и т.д.), порой выходит за рамки медицины: немалую обеспокоенность чипирование вызывает тем, что подобная практика поставит под угрозу неприкосновенность частной жизни и личных данных человека, поскольку микрочип содержит биометрическую информацию о самом носителе, а также его платежных картах и пропусках. И самый большой риск заключается в том, что со временем количество данных на чипах будет увеличиваться, поэтому людям станет все сложнее защищать свою персональную информацию. Основным аргументом в этой связи является апелляция к объективному ходу событий, к «прогрессу». Физиктеоретик С. Хокинг заявил, что человек не в состоянии «остановить прогресс или обратить вектор его движения, поэтому мы должны признать его опасности и 


\section{"Informasiya təhlükasizliyinin aktual multidissiplinar elmi-praktiki problemlori” V respublika konfranst, 29 noyabr 2019-cu il}

контролировать их» ${ }^{1}$. Но, как оказалось, контролировать прогресс куда сложнее, чем способствовать ему. Этическое право на соблюдение безопасности личной жизни, будучи юридическим воплощением принципа невмешательства в личные дела каждого, то есть выражением суверенитета человека, представляет собой очень хрупкое общественное завоевание, которому стабильно угрожают социальные и политические катаклизмы, а также огромные возможности контроля и управления, появившиеся в ходе информационного прогресса.

\section{Сегодня}

информационно-коммуникационные технологии проникают во все сферы жизнедеятельности человека, открывая безграничные просторы как для возможностей и совершенствования, так и для злоупотреблений и нарушения прав. Более того, обмен информацией является одним из стратегических компонентов развития каждой страны[2]. Потому несомненно, что в данных условиях проблема информационной безопасности приобретает выраженную актуальность. Феномен информационной опасности имеет множество форм своего проявления: от манипулирования сознанием и поведением людей, сознательной или неосознанной подмены ценностей и целей, до информационной войны и информационного терроризма. Эти процессы, прежде всего, обусловлены отношением людей к информации, потребности в ней и способности различать истинное и ложное, полезное и бесполезное. В новом информационном обществе, где человек зачастую обменивает «быть» на «казаться», границы между дозволенным и неприемлимым стираются, негативные процессы могут маскироваться в объективно-нейтральные формы своей реализации. В результате такой «подмены», человек не только не может сохранить свою идентичность, но и не в состоянии адекватно воспринять и осмыслить вызовы, угрожающие обществу.

Человек ежедневно подвергается агрессивному информационному воздействию, которое помимо его воли влияет на психику, индивидуальное и общественное сознание, в том числе на устойчивость личных и морально-психологических качеств. Только личность устойчивая способна произвести критический анализ, дать оценку воспринимаемой информации и принять объективное решение на основе этой информации. Вопрос о формировании себя как личности, а также проявлении себя в ходе самоопределения приобретает принципиальное значение в обществе информационного типа, ибо зависимость от информации «убивает» зависимость от коммуникации в форме настоящего личностного общения. Наряду с этим, расширение информационных технологий уверенно влечет за собой унификацию идеалов и взглядов, подавление всякого проявления индивидуализма и личности. Происходит «омассовление» культуры. Новая массовая культура, доставшаяся нам от XX в., есть культура потребления или консьюмеризма, идущая под девизом «чем больше вещей

${ }^{1}$ Hawking S. A Brief History of Time. London: Bantam, 2011. 256 p. и информации человек потребляет, тем больше он значит». В действительности же человек утратил чувство индивидуальности и самоценности, превратившись в живой ресурс для достижения внешних, зачастую коммерческих целей. И, как следствие, мы имеем утрату веры в человека, в самого себя, в собственные силы. Уже во-второй половине ХX столетия мыслители (Э. Фромм, Ж. Бодрийяр, Х. Ортега-и-Гассет и др.) высказали мнение о том, что стремление к покорению природы и обретению власти превратит человечество в стадо потребителей «стадо, верящее, что дорога, по которой мы идем, непременно приведет нас к желаемой цели, ибо мы видим, что и другие идут по той же дороге» ${ }^{2}$. В свою очередь, социальное развитие того или иного общества, как и его национальная безопасность во многом определяются тем, какое ценностное и культурное содержание преобладает в данном информационном пространстве. Заявление А. Швейцера о том, что человек «подчиняет свое суждение суждению массы и свою нравственность нравственности массы» $^{3}$, не теряет своей актуальности и по сей день. Ведь когда общество воздействует на индивида сильнее, чем индивид на общество, начинается деградация культуры, происходит деморализация общества, и оно становится дееспособным в понимании и решении стоящих перед ним задач и проблем. В подобных «несвободных» условиях нас не привлекает возможность быть личностью, мы неосознанно все охотнее подвергаем себя риску превратиться в человека-вещь, чувствуя себя в безопасности. В этом и состоит парадокс информационного общества: иллюзорное ощущение безопасности скрывает реальную угрозу самой человеческой природе. Эта проблема есть данность, которую необходимо решить человеку XXI в. На повестке сегодняшнего дня стоит технологизация всего и вся, вплоть до процессов творчества, его замены алгоритмами деятельности и программирования.

Информационные технологии меняют не только способы умственного и физического труда, но и способы коммуникации. Индивид социализируется, все более отчуждаясь, «идея человека» распадается, и человечество сталкивается с угрозой эмансипации, творческой деятельности и всякой критической способности в обмен на свои «системные» цели и средства. Хотя на первый взгляд отчужденность может показаться несколько далеким от процессов социализации, но на самом деле эти явления выступают как составные аспекты глобализирующегося и меняющегося общества[3]. Таким образом, парадоксальная аномалия информационного века заключается в том, что он породил два разноплановых скачка: к интеграции человечества как социальной общности, связанной всемирной сетью, и к дезинтеграции определенного общества как такового. На смену «живому» человеку приходит «виртуальный», в связи с чем возрастает его волнение о своей экзистенции; человек стремится найти выход из духовного одиночества и

2 Фромм Э. Гуманистический психоанализ / под ред. В. Лейбина. СПб.: Питер, 2002. 544 с.

${ }^{3}$ Швейцер А. Культура и этика. М.: Прогресс, 1973. 344 с. 


\section{“Informasiya tohlükosizliyinin aktual multidissiplinar elmi-praktiki problemlori” V respublika konfransı, 29 noyabr 2019-cu il}

вырождения, но даже это стремление обречено быть техническим, ибо он ищет «технологию» приобретения друзей и власти, «технологию» счастья и успеха. Человек уверен в своей свободе, безусловной способности творить себя, не понимая, что творение это происходит по уже определенным запрограммированным стандартам, ибо человек растворяется в новой реальности - реальности software.

\section{ЗАКЛЮЧЕНИЕ}

Таким образом, информационное общество порождает огромное количество этических вопросов, которые находят свое отражение, как в морали социума, так и в нравственности каждого отдельно взятого человека. Несмотря на то, что глобализация информации способствует взаимному обогащению народов, обеспечивает мгновенный доступ к информации в любой точке мира, она также размывает границы материального, цифрового и биологического миров. Проблемы информационной безопасности общества, в которых прослеживается перевод коммуникаций из сферы непосредственного контакта в сферу, опосредованную технологиями коммуникации, выходят далеко за рамки традиционных вопросов безопасности и затрагивают абсолютно все сферы жизни человека. Возникает острая необходимость в сохранении ценностей демократического общества, основанного на принципах взаимного уважения и соблюдения прав человека. В свою очередь, обеспечение информационной безопасности - это перманентный и комплексный процесс, включающий правовые, организационно-технические, политические и социальнокультурные средства и методы. В связи с этим, анализ процессов научного познания не следует ограничивать исследованием его методологических, гносеологических, и логических оснований. Необходима разработка также аксиологического базиса. Формулируемые философией гуманистические и социально-этические принципы непосредственно должны быть вовлечены в сам процесс познания, выполняя регулятивную функцию на всех его стадиях. В данном контексте существенным является изучение взаимодействия информации и морали на гетерогенных структурно-функциональных уровнях социума, в том числе в процессе совершенствования человека и преодоления этического коллапса информационной неприкосновенности его частной жизни. При этом следует учесть, что интенсивная динамика развития информационных технологий постоянно привносит новые элементы в содержание рассматриваемых проблем, что делает особенно актуальными исследования, посвященные анализу современных этико-информационных вопросов.

\section{ЛИТЕРАТУРА}

[1] В. Кутырев, «Последнее целование. Человек как традиция». СПб.: Алетейя, 2015. 312 с

[2] “Onənəvi mediadan internet mediaya doğru: problemlər, çağırışlar”. Bakı: "Elm və təhsil", 2016. $160 \mathrm{~s}$.

[3] F. Xudanlı, "Frankfrut məktəbinin sosial fəlsəfəsi". Bakı: Renessans-A, 2014. $180 \mathrm{~s}$.

\section{PHILOSOPHICAL ASPECTS OF THE IMPACTS OF INFORMATION TECHNOLOGY ON SOCIAL DEVELOPMENT}

\section{Samira Dadashova}

Institute of Philosophy of ANAS, Baku, Azerbaijan

$$
\text { samira_889_87@mail.ru }
$$

Abstract- This article discusses the most important social problems of modern society, caused by informational impacts on individual and public consciousness. The goal is to draw the attention of the scientific community to the philosophical aspect of given problem and its moral component.

Keywords - information technology, personality, manipulation of consciousness, ethics 